Eleonora SAVA

Faculty of Letters, Babeș-Bolyai University

Cluj-Napoca, Romania

norasava@gmail.com

\title{
FAMILY COOKBOOKS - OBJECTS OF FAMILY MEMORY
}

\begin{abstract}
Recommended Citation: Sava, Eleonora. "Family Cookbooks - Objects of Family Memory." Metacritic Journal for Comparative Studies and Theory 7.1 (2021): https://doi.org/10.24193/mjcst.2021.11.06
\end{abstract}

\begin{abstract}
The article proposes an analysis of family cookbooks from the perspective of memory studies. Its main goal is to show that these are objects that shape family memory, helping to preserve and transmit it from one generation to the next. The first section outlines the theoretical framework, discussing the multiple layers of content and meaning in homemade cookbooks, the similarities between them and scrapbooks, as objects that can elicit voluntary (or involuntary) memories. Other theoretical issues that are essential for the problem in question are also examined: the complex relationships between individual memory and family memory, the layers that make up family memory, how family meals shape family memory, and recipe books seen as Proustian devices. The second part proposes a case study that explores the particular way in which the aspects discussed in the theoretical section are illustrated by two recipes notebooks belonging to a woman who was born in a Romanian town in 1944 . As regards the research methodology, the case study is based on a life-story interview and the qualitative analysis of the two notebooks.
\end{abstract}

Keywords: family cookbooks, scrapbooks, individual memory, family memory, objects of memory.

\section{Family cookbooks - levels of content and meaning}

Family cookbooks are objects that gather together food, family and memory. This is why they are made up of interdependent layers of content and meaning. Like all cookbooks, they contain recipes, which are the "elementary forms of culinary life" and the "textualization of the culinary realm" (Appadurai 14, 10). This is the basic level, which refers to their practical value, that of cooking guides. Yet it should go without 
saying that this culinary realm is culturally, historically and socially shaped: what we cook/eat and how we cook/eat differ from one culture to another, from one social environment to another, from one era to another, and from one family to another. This is why the first level consists of specific culinary knowledge through which information about food is preserved and transmitted in a given context: a specific set of ingredients, a specific combination of foods, the use of specific spices and cooking techniques, etc. In connection with this, the role of cooking is to provide "a conduit of memory transmission, an embodied practice that transfers not only skill and technique but also distinct recipes or particular uses and understandings of ingredients and flavours that may have existed in the family for generations" (Shore and Kauko 106). This aspect of intergenerational transmission suggests that family cookbooks house a second level of content, namely the level of family memory, since recipes are inherited within a family and then passed on, from one generation to the next. In addition to culinary lore, family recipe books also relay a lot of other information.

First and foremost, they convey an insight into the roles entailed by food procurement and preparation, roles that tend to be gendered most of the time. These practices and roles are essential for both family building and the reinforcement of the gender binary, given that in their everyday activities, "people produce, reproduce, and legitimate gender and family" (DeVault 13). Since domestic activities - primarily feeding the family - tend to be attributed to women, it is natural that women should also be the ones who write, preserve and use food recipes. Moreover, because they are handwritten, they convey a very strong affective legacy. While the printed format of cookbooks standardizes and unifies (not only the content, i.e., the recipe itself, but also the form, i.e., the actual script), the handwriting in recipe books is likely to customize and personalize them, particularly since, as we shall see below, recipe books contain not just one, but a multitude of handwritings. Each of these works much like a photo, in the sense that just like a photo that is kept in the family album may bring back the memory of an acquaintance or a loved one and recall a certain moment in the family history, handwriting may summon the image of the person who wrote that recipe, actualizing the history of the relationship with that person or the precise experience of tasting that dish and/or eating together. Thus, the family cookbook becomes an album of memories.

Very often, recipe books also contain notes that are not related to food, but which reflect important aspects of their authors' lives. Having researched notebooks 
with recipes written over four centuries, American folklorist Janet Theophano noticed that "for hundreds of years, women of diverse backgrounds have found the homely cookbook a suitable place to record their stories and thoughts as well as their recipes" (Theophano 1). Looking for continuities in cookbooks, as well as for transformations, she observes that despite all the changes, the uses given by women to recipe books are identical over time:

The themes found in cookbooks are timeless: life and death, youth and age, faithfulness and betrayal, memory and forgetfulness. Yet cookbooks also tell us how to make beauty and meaning in the midst of the mundane - a concept especially important for women, whose lives often are punctuated by the demands of feeding others. Despite or perhaps because of their ordinariness, because cooking is so basic to and so entangled in daily life, cookbooks have thus served women as meditations, memoirs, diaries, journals, scrapbooks, and guides (Theophano 3).

\section{Family cookbooks as recipe scrapbooks}

Many family cookbooks, such as the notebooks examined as a case study in the second part of this article, are also memoirs. Both are created by women. Therefore, both are forms of female authorship which, given the memories they contain, recount personal histories. Considering the strong entwinement of individual and family memories, these personal histories become part of larger family histories.

A further aspect that should be highlighted in this context is the direct link between memory and identity. Thus, family memory is "a necessary and crucial aspect of family identity" (Shore and Kauko 85-86). Also, individual memory is essential for defining personal identity. In this regard, Janet Theophano rightly notes that both objects contribute to shaping the image and identity of the person who created them:

In their „formal” scrapbooks, women self-consciously shape their identities by selecting significant memories and preserving them in images or textual fragments. In the same way, compiled recipe books are deliberate constructions of the women who kept them. They may have seen themselves as loving mothers, devoted wives, and good friends. These were the self-images they chose to project through their recipe books (Theophano 122). 
Creating and preserving scrapbooks is defined by three component activities: "saving, organizing, contemplating and sharing" (Katriel and Farrell 4-5). In the specific case of recipe scrapbooks, collecting and preserving recipes for their utility value (saving) is followed by organizing, arranging and pasting manuscripts in a notebook, then by annotating, commenting and ornamenting them with pictures, as well as including other family memories (organizing). The level of family memory is generated both through the items themselves and through the metatext constructed in relation to them.

The third set of activities defining the process of creating scrapbooks consists of contemplating and sharing them with family members and sometimes with friends. The process of showing a recipe scrapbook to children, grandchildren, other relatives or close friends is primarily a means of preserving and passing on family memory.

\section{Family cookbooks, recipe scrapbooks, and family memory}

Both family cookbooks and recipe scrapbooks attach the subjective memories of their authors and objectify them. It is precisely by creating these objects and sharing them that individual memories become landmark memories for the members of a family. At the same time, the creation of these objects is determined by the family memory. As Maurice Halbwachs demonstrated in the first half of the twentieth century (Halbwachs, La mémoire), individual memory is socially shaped and personal memories are built through the perspective provided by the collective memory of a family group. When creating these memory notebooks/ recipe scrapbooks, their authors attribute a certain meaning to them, and this meaning is built on the basis of the social and family context in which they live. Thus, individual memory is shaped by family memory. However, family memory is not immutable, according to Halbwachs. It is recreated not only through the personal experiences of different members, but also in relation to each person's path within the life cycle. Thus, the family memories contained in these notebooks are not fixed: by transmitting them from generation to generation, they will be reworked by family members, so they will be actively modeled by those who, in turn, pass them on. What is foregrounded thus is the dynamic character of family memory. At the same time, these notebooks provide family members with a common perspective on family memory. As noted, "family memory, as is practiced by families, emerges in interaction between family members in which such material carriers of memory trigger and feature the interactive memory work" 
(Shore and Kauko 98). Accordingly, family memory is the result of permanent transactions between individual memory and collective (family) memory. Memory notebooks, as objects of memory, ultimately preserve and shape family memory.

\section{Family meals and family memory}

An important aspect is the fact that family memory is constructed in direct relation to food and family meals. Next, I will outline the mechanisms that generate and support the relationship between memory and family meals, based on a sociological and anthropological bibliography.

Beyond their practical, nutritional purpose, family meals have an important symbolic dimension, particularized through their affective, social and cultural values. First, family meals are images "of a shared life, of being together within the family, defined first by its relational and affective dimension" (Muxel, La famille 78). ${ }^{1}$ In addition to this, food sharing produces kinship ties, organizes and gives shape to relations between family members. Last but not least, commensality is "a reflective cultural institution that produced and reproduced social knowledge and collective memory through the circulation of material forms as templates of shared emotion and experience" (Seremetakis 14). Given all this, it is obvious that shared meals organize both family and family memory.

At the beginning of the twentieth century, French sociologist Maurice Halbwachs pointed out the connection between meals as an "institution" and the family, believing that the family meal was the very essence of family life (La Classe 289). Based on this, in the second half of the twentieth century, meals and families came to be regarded as interrelated systems, which reinforced one another. Continuing French anthropologist Claude Lévi-Strauss's structuralist approach to food analysis, British anthropologist Mary Douglas analyses the connections between "the food system" and "the social system," showing that commensal eating patterns reflect the social relationships between individuals: "If food is treated as a code, the messages it encodes will be found in the pattern of social relations being expressed" (Douglas 61). In her famous Deciphering a Meal, she demonstrates that family meals are patterned activities and that they structure family life. Research conducted by sociologists, based

\footnotetext{
1 « Le repas (...) donne existence et réalité à la représentation d'une vie partagée, d’un être ensemble saisi dans le cadre d'une famille définie d'abord par sa dimension relationnelle et affective » (My translation).
} 
on methodologies specific to the discipline, came to similar conclusions. Thus, at the end of the twentieth century and in the first decades of the twenty-first century, French sociologist Anne Muxel argues that meals organize and shape family life, setting its internal order (Muxel, La famille 78, 80-1).

Another important idea shared by most of the social-cultural anthropologists who have studied family meals is that common meals produce bonding and that, most often, they are family bonds. Starting from the early twentieth-century theorizations of French sociologist Émile Durkheim, who showed that in many societies of the past communal meals created kinship ties (natural and/ or artificial), sociologists and contemporary anthropologists argue that, just like in archaic societies, commensality has the value of blood ties. Thus, French socio-anthropologist Claude Fischler states that "In apparently all cultures, eating the same food is equated with producing the same flesh and blood, thus making commensals more alike and bringing them closer to each other" (Fischler 536). In turn, French sociologist Jean-Claude Kaufmann shows that food sharing has produced and continues to produce social ties in all societies. While in archaic societies "the primordial forms of kinship were predicated on the idea of familiarity that is released through the sharing of food," in contemporary societies "kinship is constructed 'by porridge' and by sharing food day after day" (Kaufmann 65, 299). ${ }^{2}$ From this point of view, family meals are rituals meant to build up, maintain and strengthen affective and kinship ties among family members. It is obvious, therefore, that family memory is very closely related to family meals. In this regard, Pascal Lardellier, a specialist in communication anthropology, believes that the family meal is the "true hub of the home, the heart of the family around which family memory is written, regenerated, perpetuated" (Lardellier 47). 3 Working for a long time on family memory and on memories of childhood or later family life activated by individuals, sociologists Anne Muxel found that what people remember first and foremost are family meals (La famille, 82). This idea also appears in studies by contemporary American historians and anthropologists, such as John R. Gillis or Bradd Shore, and Sara Kauko, who argue that family meals are important means of

\footnotetext{
2 «Les formes primordiales de la parenté (...) ont été concrètement fabriquées par l'idée de familiarité se dégageant du partage des repas» (Kaufmann 65). «Comme au temps des premières sociétés, le parenté se construit toujours par la bouillie, en partageant la nourriture, jour après jour» (Kaufmann 299) (My translation).

3 «Le vrai centre de la maison, le cœur de la famille, c'est la table de la bien nommée salle à manger. C'est là qu'elle se retrouve pour produire son histoire, c'est autour de cette table qu'un mémoire familiale s'écrit, se régénère, se perpétue» (My translation).
} 
creating family memories: "Family rituals such as family dinners..., special meals... are significant ways in which families actively create frameworks for joint memory and narrative among family" (Shore and Kauko 99).

At the same time, commensality is closely related to family memory through the sensory experience of food: taste, smell, but also sight, hearing, the sense of touch, as well as the synesthesia produced by combining the senses. Cultural anthropologist Nadia Seremetakis highlights the close relationships between senses, practices of commensality, and memory: "Commensality can be defined as the exchange of sensory memories and emotions, and of substances and objects incarnating remembrance and feeling" (Seremetakis 14).

\section{Family cookbooks as Proustian devices}

Family memory is multilayered. To describe its content, Anne Muxel uses the image of a Russian doll for, like it, family memory consists of concentric circles or successive layers. The first layer, the deepest and most enduring through time, is that of sensory memory: "It forms the core of the individual's familial memory. Because it is maintained within the sensory body experience itself: smell, sound, touch, etc., its content cannot be erased. The senses fix the memory" (The Functions 24). These are, therefore, emotionally charged memories which, though apparently forgotten, can be brought back to the surface through some present sensory stimulus. 4

In relation to the level of sensory memory, family cookbooks work, as noted, like "Proustian devices" (Appadurai 18). Like a madeleine soaked in lime-blossom tea, the taste and smell of which triggers a process of childhood remembrance in the Proustian narrator, the recipes in a family notebook can summon images of scenes or people - with their entire emotional halo, with their past atmosphere and setting through an involuntary recollection process triggered by the senses. However, in this case, memory is not conjured by tastes or smells in praesentia, but by tastes and smells that are stimulated through sight, when we read recipes, as transpositions of food at a linguistic and scriptural level: "Our eyes let us 'taste' food at a distance by activating the sense memories of taste and smell" (Kirschenblat-Gimblett 3). More than that, reading recipes involves not only a vicarious experience of taste and smell, but the pleasure of eating itself: "Cookbooks... are a way of eating by reading recipes... Indeed,

4 The reactivation of memories is not a reliable, but an unpredictable process. 
experienced readers can sightread a recipe the way a musician sightreads a score. They can 'play' the recipe in their mind's eye" (Kirschenblat-Gimblett 3).

In reality, the senses always appear associated in various combinations. When we eat or drink, we perceive food or drink simultaneously through sight, taste, smell and touch, and this is also demonstrated by sensory neuroscience. Still, it is smell that makes the largest contribution to experiences we have when tasting (Smith 39). 5 The communion of the senses occasioned by food was called synesthesia by anthropologists (Sutton; Korsmeyer and Sutton, etc.). Thus, American anthropologist David E. Sutton considers synesthetic interactions between the senses "a key to food memories through the notion that memory has multiple interacting sensory registers" (Sutton 218). Reading recipes can activate this sensory heap which, in turn, can trigger a series of strong memories, emotions and experiences stored in the past. As Nadia Seremetakis suggests:

Sensory memory is a form of storage. Storage is always the embodiment and conservation of experiences, persons and matter in vessels of alterity. The awakening of the senses is awakening the capacity for memory, of tangible memory; to be awake is to remember, and one remembers through the senses (Seremetakis 4).

In keeping with Seremetakis's research, David Sutton considers food a particularly fertile site for examining memory and suggests that memory itself can be approached as a sense. Thus, he refers to the senses as

a type of communicative and creative channel between self and the world, rather than the traditional view of senses as passive receptors of data. This ... applies to memory as well: both memory and senses are now being conceptualized as active, creative, even transformational cultural processes, not simple receivers of empirical information (Korsmeyer and Sutton 471).

\footnotetext{
5 In Proust, the Madeleine and Memory, philosopher of the senses Barry C. Smith argues that "smell has a special capacity to trigger memories ... because of the direct connections olfaction has with the limbic system involved in generating emotions and memory... It is smell's link to brain areas involved in emotions and memory that gives aromas the power to invoke emotionally charged memories from our pasts. In this respect, Proust's original madeleine episode shares an explanation with the Proust Phenomenon we talk about today when we say that smelling a particular scent «takes us right back» to an earlier time" (39-40).
} 
Meals, as well as food recipes, evoke by analogy other meals similar to the one recalled. "The advantage of thinking of memory as a sense would be to highlight not only the role of analogy, but how those analogies create channels of communication between past and present moments" (471). Viewed through this lens, the Proustian madeleine does not recall an ossified memory that has sedimented in the past but creates a conduit of communication between the past and the present. Specifically, the associated senses - the primary of which is the smell - re-create an episode of the past. Thus, memory is infusing the present, and "memories from the past combine with present impressions to spur future actions" (472).

\section{Two family recipe books as objects of family memory. A case study}

The case study forming the applied section of this paper highlights the particular way in which the elements discussed in the theoretical section are illustrated in two recipe books belonging to Mrs M., born in a Transylvanian town in Romania, in 1944. I will be interested, first of all, in identifying the specific way in which family memory is built, preserved and transmitted through these notebooks and to check whether they really function as objects of individual and family memory. Given this goal, the research will not address the items in the two recipe books from a gastronomic perspective, but from the perspective of memory studies. As regards the research methodology, the study is based on a life-story interview with the author and on the qualitative analysis of the two recipe notebooks.

Two things stand out when we take these notebooks into our hands. The first is that they are neat-looking and quite appealing: Mrs M. always takes care to supplement the recipes with images from food and cooking magazines, to match the colours of the clippings, to please the reader's eye. The second essential thing is the thoroughness with which the information that accompanies the recipes themselves and the other items is recorded. Her organizational spirit, her rigorous manner of dating and contextualizing everything have led her to write down on the cover of the notebooks not only the year (2011), but also the date (December 25). As seen below, the dates are relevant to the meaning that the author assigns to these objects. In 2011, she was 67 years old and had already been cooking for several decades, so she was a housewife with a lot of experience in the kitchen. Unlike other women who write down their food recipes in notebooks because they want to learn how to cook, Mrs M. makes up these recipe books primarily taking into account their memorial purpose. 
Pragmatic purpose ranks second, as she confesses: "I filled out these recipe books as memoirs."

Conceived in this way, the two notebooks belong to the category of feminine autobiographical texts. Just like the practice of creating recipe books, the practice of creating memory notebooks is "a gender-specific activity," closely related to the "traditional feminine role-assignation as a custodian of matters private and familial" (Katriel and Farell 3). While memory notebooks are usually considered autobiographical "texts," cookbooks are not autobiographies, strictly speaking. But they are filled with details about the life and work of their authors, thus being "one of a variety of written forms, such as diaries..., that women have adapted to recount and enrich their lives" (Theophano 122). Therefore, in addition to their memorial purpose, Mrs M.'s notebooks are a way for her to shape her own image and present herself to her descendants. The self-image created in these notebooks reveals her as a good wife, a loving mother, and a good friend, but also as a person deeply attached to her family's memory. Love and devotion to the family, the permanent effort to care for family members, talent and culinary experience (manifested in the skill of cooking very diverse and often complicated dishes), respect for the family and its values (reflected in her endeavour to preserve and hand down her family's culinary heritage and other memories of extended family members), aesthetic taste (highlighted by the care to display this legacy as beautifully as possible) are just some of the elements of the selfimage she has built through these two notebooks. Besides building this self-image, notebooks also shape family memory.

From the point of view of the elaboration process, we find all three stages that define the creation of scrapbooks: saving the recipes and other family documents, organizing them in two notebooks, followed by sharing them with family members.

Saving refers, in this case, to the fact that Mrs M. has collected the food recipes she has received from female relatives and friends for almost 50 years. She waited for the right moment to arrange them in a final format, in the two notebooks. When this memorial work started, she was living just with her husband. Her son had moved to a different town, along with his wife and two daughters, who were teenagers at the time. Her mother, with whom she had lived all her life, had died a year before, and her father and brother had passed away as well. Mrs M. had retired, so opportunities to meet her coworkers had become rare, and the intensity of her social life had diminished. Here she was on December 25, the first Christmas day of 2011. Having retreated to the 
holiday home, winter holidays found her for the first time in the company of just her husband, without their extended family, as in previous years. This was the time when she decided to put together the recipe papers, but also other family papers (which did not contain recipes) that had been collected since the 1960s and kept in large envelopes. She took them with her to the holiday home, and while her husband "who was a great, very great reader of books of history and culture, was reading" (as she testifies in the interview), Mrs M. arranged the papers and then placed them onto the pages of two large notebooks, with pages slightly larger than the A4 format. She "compiled" them, as she says, that is, she ordered them, glued them in, and annotated them - precisely because the extended family was physically absent from the Christmas dinner table. These papers, which had been kept in the kitchen drawers for decades, began a new life, as they were beautifully and carefully placed in recipe books when the family dissipated and when meetings with colleagues and friends became scarcer. The restriction and reorganization of the family became the ground for the creation of an "imagined family" (Gillis), through the lens of nostalgia. The commensality of the old Christmas dinners was to be symbolically substituted by this "composition," which represented an idealized image of the family gathered around the table. As scrapbooks typically contain "memorabilia of good moments and precious times, but also a sense of the life as perfect, as well-lived" (Katriel and Farell 5), the notebooks in question selected those moments in family history that had something to do with food. If most scrapbooks are chronologically organized, another type of scrapbook "tends to focus upon a single theme..., or topic as an anchor for identification" (4): food, in this case. It is not by chance that food is the one thing around which both the image of the author and the memory of the family are built. As we have shown in the theoretical section, everyday meals "make the family" (Kaufmann 93 passim), festive dinners are memorable occasions, and the sensory experiences of food are part of the deepest layers of individual and family memory.

Organizing implies incorporating the saved items into a new text, "which has a place and function in the owner's present life" (9). Mrs M. ordered the recipes, according to her sense of taste, in two suggestively titled notebooks: "Sweet Recipes" (comprising 354 items) and "Savory Recipes" (642 items). In addition to food recipes, the notebooks also contain other papers kept by Mrs M., which provide information about her family's life. 
Handwritten recipes are pasted on the pages of the notebooks, forming a collage. The preservation of handwriting is a way to reify the memory of loved ones who cooked in families - mothers, aunts, other relatives. Their presence comes alive in the recipes. Thus, a handwritten text contains not only culinary indications, but also conjures the image of the person who wrote it. It may also evoke the image of the family gathered around daily or festive meals. At this level, we can talk about a symbolic reconstruction, since "the meaning of family has been radically transformed from a group of people one lives with in the here and now to an imagined entity we live by through either a remembered past or a dreamed of future." (Gillis 2).

On each recipe, Mrs M. noted both the name of the person who wrote it and the position that that person occupies in relation to the author and to the family genealogy. Here are some examples. The following words are scribbled next to a handwritten recipe for vanilla croissants: “from Maia..., my mother-in-law, R's mother....” A recipe for sheet cake is accompanied by this explanation: "from Aunt Margareta, Bibi's older sister." Underneath a cheesecake recipe she has noted: "from Magda M., wife of H..., cousin of R..." It is clear therefore that the author of the notebooks has taken very great care to offer both the name of the person (Maia, Margareta, etc.), sometimes even the surname (Magda M., Christa P., etc.), and their kinship degree (mother-in-law, aunt, etc.), or their position within the broader network: "my mother-in-law, mother of R.” (R. is the author's husband); “aunt..., Bibi's older sister" (Bibi is the author's mother) or "wife of H., cousin of R." All this detailed information works by providing "cognitive anchors for family identity" (Shore and Kauko 96) and is addressed to future generations. By recording them, the author expresses implicitly her intention to pass on (also) through these notebooks information about her family, for "kinship terminologies and genealogies function as mnemonics for structuring family memory and provide mental maps for individuals to coordinate their family identities with others" (96). The main goal of these mnemonics is "to allow people to remember and identify each other as relatives or ancestors of one kind or another," and consequently to preserve and transmit family memory, as "a necessary and crucial aspect of family identity" (85-6).

In addition to food recipes, the notebooks contain other relevant information about family life. The book of sweet recipes opens with a page written by Mrs M.'s mother. Here is the transcript: “1969. New Year's Eve with Ticu. Engagement. Freezing hallway. Flu... Plus Bubu... The carpet... The kids' wedding. The fight about the 
bicycle." The recorded events appear to be a page in the journal that Mrs M.'s mother kept in 1969. They extremely succinctly present the personal and family events of that year: the engagement and wedding of Mrs M., the illness of family members (flu), consequences of weather phenomena on the household (freezing of the hallway), a quarrel in the family, as well as information about names that are suggestive of family intimacy: Ticu (the father of Mrs M.), Bubu (the uncle of Mrs M., her mother's brother). Certainly, these events marked both the mother, who wrote them down in her diary, and Mrs M., since she chose to start the recipe book with these memories.

The last pages of the notebook contain memories of D., the son of Mrs M.: a childish drawing depicting a car, next to which the author of the notebook wrote "Daktari's car, drawn by D. (4 years old) 1974," and later added: "D. 4 years old" (Image 1). Another page joins in a collage a poem for children that her son recited in kindergarten and a page from his calligraphy notebook, bearing the mention "School: D. in first grade" (Image 2). The following page contains another poem for children, in Mrs M.'s handwriting. The following information appears on it: "1999. Little girl poems." These were poems written for the two granddaughters, who were 4 years old and went to kindergarten in 1999.

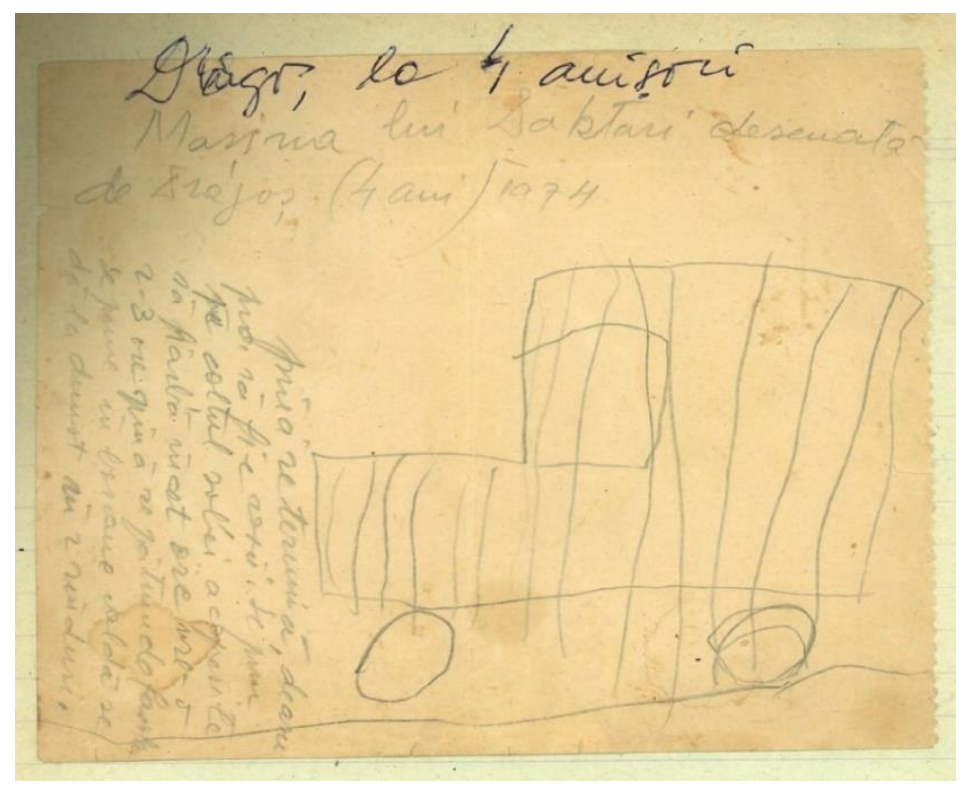

Image 1 


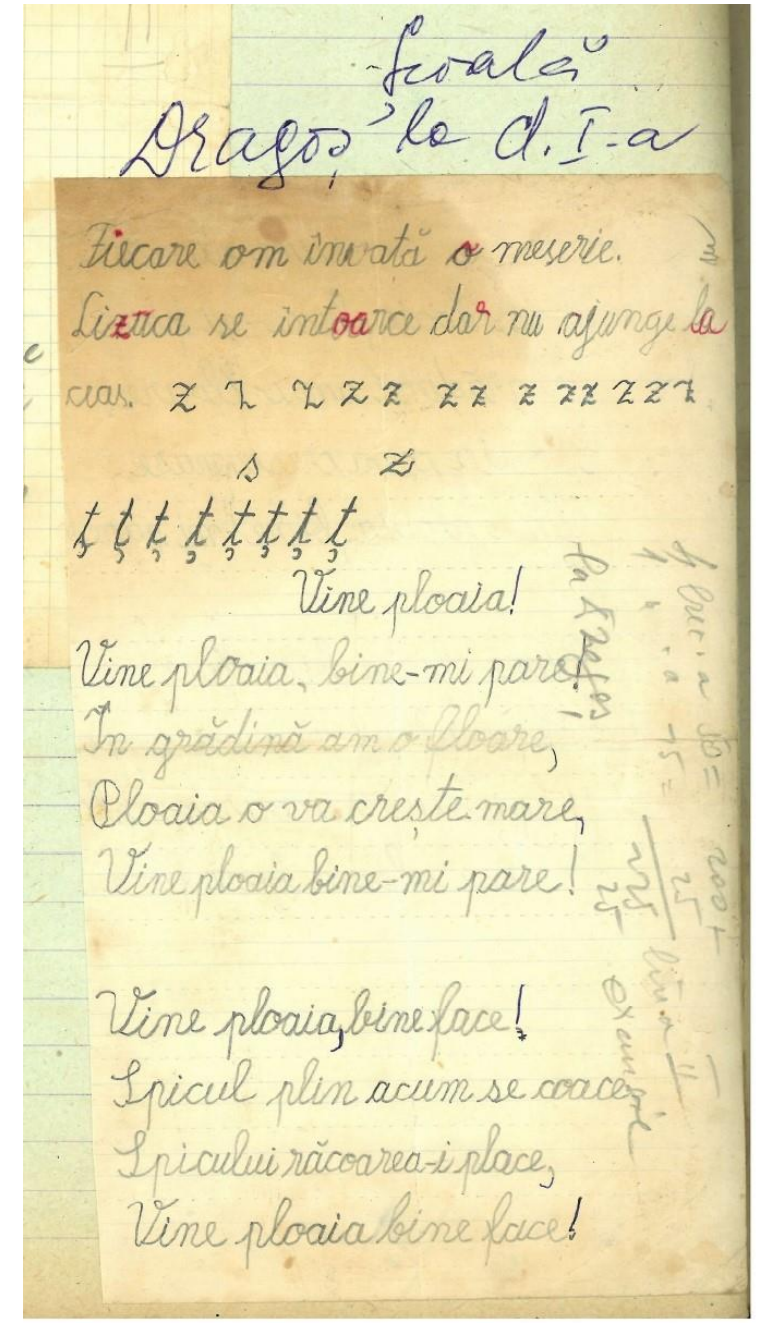

Image 2

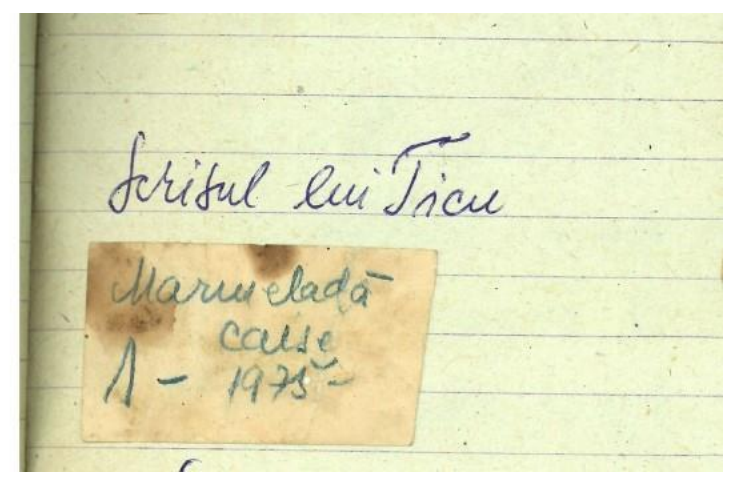

Image 3

So here are four generations of the family (Mrs M., her mother, her son, and her granddaughters) gathered together in the book of sweet recipes. Important events in the history of the family (mentioned on the first page), significant moments in the development of children (on the last pages) are immortalized like in a photo album. In fact, the explanations accompanying these manuscripts are identical to those jotted down on the margins of family photos. For example, mentions such as "D. at 4 years old" or "D. in first grade" suggest that the drawing/manuscript conveys an image of her son at that age (the place of the photographic images of people being taken by the handwriting of each family member).

At the end of the notebook there is also a page that holds the father's writing, also on an inscription related to food: "Apricot Marmalade 1-1975." This is accompanied by Mrs M.'s explanation: “Ticu's handwriting” (Image 3). Her brother's handwriting appears on the same page - this time, not as a culinary-related fact, but 
as an excerpt from a letter about the end of the summer holidays, sometime in the 1970s. Next to it Mrs M.'s has scribbled: “Memory of P's handwriting.” By including these handwritten fragments in her recipe books, Mrs M. managed to capture significant memories related to family members who had never cooked (father, brother) or who had never cooked before: her two granddaughters.

Through all these elements - the selection of food recipes transmitted in the family and of other documents that are representative for family life, their organization and inclusion in the two notebooks, their commentaries and annotations - Mrs M. has built a narrative about herself and her family. Thus, she has shaped herself into a generator of family memory, and her recipe books have become a symbol of home and family. The two objects work as "Proustian devices," in the sense that the recipes establish a communication channel between the past and the present on two levels: that of the content and that of the form. When the content of a recipe is read, the present can be infused with memories activated through the senses of the "mental consumption" of the described dish. As regards the written form of the recipe, the handwriting works like a photo that re-creates images from that person's past.

Sharing. Taking into consideration the fact that food recipes have a practical function, Mrs M. still uses the recipes in these notebooks when cooking. Still, her intention, when she created the notebooks, was to pass them on to her two granddaughters. Creating these memory objects and sharing them with subsequent generations (son, daughter-in-law, granddaughters) highlights that form of memory that is "prospective," in the sense that it involves "a family's conscious need and desire to ensure the group's future memorability" and also "a strong desire to provide stability and continuity for the idea of family in the future" (Shore and Kauko 103).

\section{Conclusions}

Both the theoretical approach and the case study revealed the complexity of family cookbooks and their potential to crystallize, preserve and transmit family memory. The analysis of homely cookbooks has revealed their similarities with scrapbooks and outlined the existence of a hybrid type, namely recipe scrapbooks. These are material objects that tell intricate histories: they may contain, in turn, a family's culinary heritage, the kinship relationships between family members, the memories of family members preserved by handwriting, the memory of family meals, as snippets of the happiness of yore, as well as other memories related to food and activated by sensory 
memory. All these are powerful anchors of both individual and family memory, because individual memory is conditional upon and intimately connected with family memory. Moreover, the analysis has shown that family memory is a complex system that has the ability to materialize into objects of memory, cookbooks and recipe scrapbooks being some of them. Because of the complexity of the topic, further research and analysis are to be undertaken.

\section{References:}

Appadurai, Arjun. "How to Make a National Cuisine: Cookbooks in Contemporary India." Comparative Studies of Society and History, 30. 1 (1988): 3-24.

Boutaud, Jean-Jaques. "La table, communication symbolique et métaphore de la communication." L'imaginaire de la table. Convivialité, commensalité et communication. Ed. Jean-Jaques Boutaud. L’Harmattan, 2004: 11-20.

DeVault, Marjorie. Feeding the Family: The Social Organization of Caring as Gendered Work. University of Chicago Press, 1991.

Douglas, Mary. "Deciphering a Meal." Daedalus. Journal of the American Academy of Arts and Sciences, 101. 1 (Winter, 1972): 61-81.

Durkheim, Émile. Formele elementare ale vieții religioase [Les formes élémentaires de la vie religieuse]. Translated by Magda Jeanrenaud and Silviu Lupescu. Polirom, 1995 [1911].

Fischler, Claude. "Commensality, Society, and Culture." Social Science Information, 50. 3-4 (2011): 528-48.

Gillis, John R. "Our Imagined Families: The Myths and Rituals We Live By." The Emory Center for Myth and Ritual in American Life Working Paper. 7 (2002): https://gdesseniorseminarfall2011.files.wordpress.com/2011/o9/imaginedfamilies.pdf

Goodsell, Todd L., and Liann Seiter. "Scrapbooking: Family Capital and the Construction of Family Discourse." Journal of Contemporary Ethnography, 40.3 (2011): 318-41. 
Halbwachs, Maurice. La classe ouvrière et les niveaux de vie. Recherches sur la hiérarchie des besoins dans les sociétés industrielles contemporaines. Félix Alcan, 1913, Édition électronique, Livre III. URL:

http://classiques.uqac.ca/classiques/Halbwachs maurice/classe ouvriere/clas se ouvriere.html

---. La mémoire collective. 1950, Édition électronique, URL: http://www.uqac.uquebec.ca/zone3o/Classiques des sciences sociales/inde x.html

Katriel, Tamar, and Thomas Farrell. "Scrapbooks as cultural texts: An American Art of Memory." Text and Performance Quarterly, 11.1 (1991): 1-17.

Kaufmann, Jean-Claude. Casseroles, amours et crises. Ce que cuisiner veut dire. Paris, Armand Colin, 2005.

Kirschenblat-Gimblett, Barbara. "Playing to the Senses: Food as a Performance Medium." Performance Research: A Journal of the Performing Arts, 4.1 (1999): 1-30.

Korsmeyer, Carolyn, and David Sutton. "The Sensory Experience of Food." Food, Culture, Society, 14. 4 (December 2011): 461-75.

Lardellier, Pascal. "La table familiale, sa scène et ses coulisses." Risques, rites et plaisirs alimentaires, by Pascal Lardellier. Éditions EMS, 2013: 47-53.

Muxel, Anne. "La famille à table." Se nourrir. Alimentation en question. Ed. Michel Wieviorka. Éditions Sciences Humaines, 2007: 75-94.

---. "The Functions of Familial Memory and Processes of Identity." Peripheral Memories. Public and Private Forms of Experiencing and Narrating the Past. Ed. Elisabeth Boesen, Fabienne Lentz, Michel Margue et al. Transcript Publishing, 2012: 21-32.

Seremetakis, Nadia. "The Memory of the Senses: Historical Perception, Commensal Exchange and Modernity." Visual Anthropology Review, 9.2 (1993): 2-18.

Shore, Bradd, and Sara Kauko. "The Landscape of Family Memory.” In Brady Wagoner (ed.). Handbook of Culture and Memory. Oxford University Press, 2017: 85-116.

Smith, Barry C. "Proust, the Madeleine and Memory." Memory in the Twenty-First Century: New Critical Perspectives from the Arts, Humanities, and Sciences. Ed. Sebastian Groes. Palgrave MacMillan, 2016: 38-41.

Sutton, David E. "Food and the Senses." Annual Review of Anthropology, 2010: 20923. 
METACRITIC JOURNAL FOR COMPARATIVE STUDIES AND THEORY 7.1

Theophano, Janet. Eat My Words. Reading Women's Lives through the Cookbooks They Wrote. St. Martin's Press ebook, 2003. 